\title{
Sancho reacentuado y \\ su teoría de la mente ${ }^{1}$
}

\section{(Reaccentuated Sancho and His Theory of Mind)}

\author{
Tatevik Gyulamiryan ${ }^{2}$ \\ Hope College, Michigan, Estados Unidos
}

\begin{abstract}
RESUMEN
Desde la publicación y las traducciones de la mayor novela cervantina el Quijote, varios autores han escrito y reescrito, recreado y reacentuado las imágenes del amo y escudero. En su obra de teatro El viaje infinito de Sancho Panza, Alfonso Sastre reacentúa y redistribuye los papeles de don Quijote y Sancho Panza. El artículo presenta un análisis de la cognición de Sancho reacentuado y concluye que debido a su teoría de la mente que se preserva en El viaje infinito de Sancho Panza, el lector no es capaz de marcar la diferencia entre el Sancho de Cervantes y el de Sastre.
\end{abstract}

\begin{abstract}
Since the publication and translations of the greatest Cervantine novel, Don Quixote, various authors have written and rewritten, recreated and reaccentuated the images of knight and squire. In his play The Infinite Journey of Sancho Panza, Alfonso Sastre reaccentuates and redistributes the roles of Don Quijote and Sancho. This article presents an analysis of the cognition of reaccentuated Sancho and concludes that due to his theory of mind, preserved in Sastre's work, the reader cannot differentiate between Sancho of Cervantes and Sancho of Sastre.
\end{abstract}

Palabras clave: El Quijote, Miguel de Cervantes, Alfonso Sastre, teoría de la mente, Sancho Panza

Keywords: Don Quixote, Miguel de Cervantes, Alfonso Sastre, theory of mind, Sancho Panza

1 Recibido: 27 de enero de 2020, aceptado: 24 de marzo de 2020.

2 Department of World Languages and Cultures. Correo electrónico: gyulamiryan@hope.edu

LETRAS 69 (2021), ISSN 1409-424X; EISSN 2215-4094

DOI: http://dx.doi.org/10.15359/rl.1-69.1

www.revistas.una.ac.cr/index.php/letras 


\section{Introducción}

La influencia del Quijote en la literatura occidental ha sido significativa. A partir del siglo XVII, cuando las dos partes de la obra ya se habían traducido a varias lenguas y estaban disponibles para los lectores, aparecen obras literarias que demuestran un trabajo intertextual a partir de la novela de Cervantes. La mayoría de las obras que revelan influencia del Quijote ofrece varios estudios de posibles interpretaciones de los textos derivados del original de Cervantes: razones de adaptación, comparación de los personajes recurrentes y contextos similares. Teniendo en cuenta el efecto del Quijote en la literatura, el presente trabajo examina la adaptación de los personajes de don Quijote y Sancho Panza en el teatro español del siglo xx, particularmente en la obra de Alfonso Sastre, El viaje infinito de Sancho $P a n z a$. El presente análisis parte del acercamiento de la reacentuación y la capacidad cognitiva de los personajes literarios, para descubrir cuán diferentes se presentan los personajes reacentuados con respecto a los originales. Para ello, es necesario definir el concepto de reacentuación y examinar la teoría de la mente exhibida en Sancho Panza en las obras de Cervantes y Sastre.

La literatura moderna abunda en obras quijotescas ${ }^{3}$ de diferentes géneros derivados de Cervantes. Entre muchos ejemplos, varias obras de la España del siglo xx introducen personajes quijotescos o reacentúan a don Quijote o a Sancho. Entre ellos se encuentran Niebla, de Miguel de Unamuno, La nueva salida del valeroso caballero D. Quijote de la Mancha: tercera parte de la obra de Cervantes, de Antonio Ledesma Hernández, El pastor Quijótiz, de José Camón Aznar, en que los autores reacentúan la imagen del Quijote ${ }^{4}$. El término

3 Las obras quijotescas son las que aluden directa o indirectamente, consciente o inconscientemente, al Quijote. Howard Mancing, «Don Quixote: Coming to America», Cervantes y su mundo (Kasel: Reichenberger, 2005) 412.

4 Miguel de Unamuno, Niebla, Mario J. Valdés, ed. (Madrid: Cátedra, 1987); Antonio Ledesma Hernández, La nueva salida del valeroso caballero D. Quijote de la Mancha: tercera parte de la obra de Cervates (Barcelona: Casa Editorial Lezcano, 1905); José Camón Aznar, El pastor Quijótiz (Madrid: Espasa, 1969). 
reacentuar o reacentuación aparece por primera vez en la obra de M. M. Bakhtin ${ }^{5}$, quien lo define como los cambios contextuales que se efectúan en un personaje conocido en distintas obras ${ }^{6}$. Es decir, la reacentuación, en la literatura, es el cambio de las características de un personaje original y para introducirlo en un contexto diferente. Bakhtin reclama que el Quijote ha sido reacentuado varias veces y en distintos contextos, y esa es una de las muchas razones por las que la novela sigue siendo una obra maestra?

Para reacentuar a Sancho Panza, hay que identificar las características que lo definen como personaje. Al principio, Sancho se destaca por su realismo, simplicidad y sus instintos básicos humanos. Con el desarrollo de la novela, va conociendo a su amo y adaptándose a su manera de ser. Al aprender el ingenio de don Quijote, se hace capaz de manipular a su amo e influir sus decisiones y acciones. Entonces, si al principio de la novel el papel de Sancho consiste en indicar la realidad a su amo, en la segunda parte $^{8}$, es quien se aleja de la reali-

5 Mikhail M. Bakhtin, The Dialogic Imagination: Four Essays, Michael Holquist, ed. (Austin: University of Texas Press, 1981).

6 En The Dialogic Imagination, Bakhtin explica la causa de la facilidad de la reacentuación de ciertos personajes literarios. Como plantea él: «The hero's discourse about himself and about his world fuses organically, from the outside, with the author's discourse about him and his world. With such an internal fusion of two points of view, two intentions and two expressions in one discourse, the parodic essence of such a discourse takes on a peculiar character: the parodied language offers a living dialogic resistance to the parodying intentions of the other; an unresolved conversation begins to sound in the image itself: the image becomes an open, living, mutual interaction between worlds, points of view, accents. This makes it possible to reaccentuate the image, to adopt various attitudes toward the argument sounding within the image, to take various positions in the argument, and consequently, to vary the interpretations of the image itself. The image becomes polysemic, like a symbol» (Bakhtin, 409-10).

7 Bakhtin (1981), 410.

Hay varios ejemplos de don Quijotes reacentuados, por ejemplo, el personaje de Madame Bovary en la novela homónima de Gustave Flaubert. A Emma Bovary no le agrada su vida cotidiana, y para saciar la escasez de amor y felicidad en casa, ella empieza a leer novelas románticas. Esas novelas llenan su mundo con ilusiones irreales y mágicas acerca del amor. Así empiezan sus aventuras en busca del amor real. Al final, por sus quimeras, Emma Bovary sufre una destrucción irremediable y se quita la vida. Como don Quijote, Emma es una apasionada lectora, soñadora, aventurera y amante. Gustave Flaubert, trans. Margaret Mauldon, Madame Bovary (Overstall: Oxford University Press, 2004).

8 Howard Mancing, The Chivalric World of Don Quijote: Style, Structure, and Narrative Technique (Columbia: University of Missouri Press, 1982) 49. 
dad para maniobrar la situación a su gusto ${ }^{9}$. El Sancho reacentuado, consecuentemente, encarna su simplicidad emparejada con su profundo entendimiento de la psicología de don Quijote.

En el teatro español del siglo xx, las figuras de don Quijote y Sancho Panza se representan en el contexto contemporáneo y moderno, siendo comprensibles para el público de la época. En El viaje infinito de Sancho Panza (1984), Sastre representa a Sancho como su personaje principal. Un lector familiarizado con el Quijote espera ver un Sancho subordinado, respetuoso, pero también gracioso y a veces ignorante. Sin embargo, aquí se ve un cambio en los papeles de don Quijote y su escudero. El escudero manda, dirige e influye, y don Quijote obedece y atiende los mandatos de Sancho. En Sastre, Sancho no sigue su trayectoria convencional, en que el escudero no manda directamente a su amo ni dirige sus acciones ex profeso desde el principio. Sastre nos presenta un Quijote al revés.

El viaje infinito de Sancho Panza es una reescritura del Quijo$t e^{10}$. La mayoría de los nombres mencionados y de los personajes ya había aparecido en la obra de Cervantes. Un número considerable de los hechos y acontecimientos también se deriva de la novela original. Leídas las obras de Cervantes y de Sastre, se nota que varios personajes coinciden en ambas obras: casi todas las acciones de Quijote se repiten en El viaje infinito de Sancho Panza; las metas, ajustes y los modos usados son muy congruentes en ambas obras. Lo que Sastre ha cambiado del texto original son el lenguaje, las funciones de los personajes y algunos otros aspectos, resultado de su propia invención ${ }^{11}$.

9 Para más estudios sobre la teoría de la mente de Sancho y su inteligencia maquiavélica, véase Isabel Jaén, «Cervantes and the Cognitive Ideas of His Time: Mind and Development in Don Quixote», Cervantes: Bulletin of the Cervantes Society of America 32, 1 (2012): 71-98, DOI: https://doi. org/10.1353/cer.2012.0004; y Howard Mancing, «Sancho Panza's Theory of Mind», Theory of Mind and Literature (West Lafayette: Purdue University Press, 2011) 123-32.

10 Cabe señalar que la reescritura no es una simple copia del Quijote, como el caso de Jorge Luis Borges, «Pierre Menard, autor del Quijote», Ficciones (Caracas: Ayacucho, 1993) 17-22. La reescritura de la obra, en este sentido, incluye la noción de la recontextualización, la cual ocurre a causa del cambio del contexto sociohistórico, y, obviamente, la reacentuación de los personajes principales de la obra cervantina.

11 Un ejemplo será el nombre del pueblo de la Mancha donde vive Quijote: Valdepeñas. 
Lo que se resalta en la obra de Sastre, que apunta en el título, es la imagen de Sancho. En El viaje infinito de Sancho Panza, se presenta al personaje muy diferente del de Cervantes. Aquí Sancho se apropia de la situación y tiene una voz definitiva, absoluta y decisiva. Inicialmente, este cambio de papeles entre don Quijote y Sancho Panza produce la desfamiliarización del lector ${ }^{12}$. Esta conversión sucede a causa de la actitud más segura de Sancho. El escudero muestra más autoridad, especialmente en la primera parte.

En lo que sigue se analiza la imagen de Sancho en el Quijote, comparando y contrastándola con su imagen reacentuada que aparece en la obra de Sastre. Al analizar la teoría de la mente del personaje Sancho original y del personaje Sancho reacentuado postulamos que, aunque el Sancho de Sastre se percibe como un personaje diferente del cervantino, su psicología, en particular la teoría de la mente, no cambia, y el protagonista del Viaje infinito queda propenso a una lectura no única o simplemente adaptada, sino una lectura vinculada a la obra de Cervantes.

\section{El Sancho Panza de Cervantes y su teoría de la mente}

El Sancho de Cervantes se nos presenta con una cognición ${ }^{13} y$ sensatez únicas. A través de los sucesos y a lo largo del desarrollo de la novela, se entera de la personalidad, los pensamientos y manera de imaginar y actuar de su amo. De esa forma, se apropia de un

12 Bakhtin critica el uso de la palabra desfamiliarización en las teorías de Shklovsky (y lo que él llama desautomatización). Él plantea que la desfamiliarización en literatura no es sólo el concepto de hacer algo extraño. Este concepto reta nuestro conocimiento previo sobre algún aspecto sociológico, histórico o cultural. Como el arte y la literatura son dinámicos, la desfamiliarización no es un concepto fijo. Nos desfamiliarizamos de los conceptos y nos familiarizamos con ellos de la misma manera. Mikhail M. Bakhtin, P. N. Medvedev, The Formal Method in Literary Scholarship (Baltimore: John Hopkins University Press, 1991) 6061, 97. En el caso de Sancho Panza en la obra de Sastre, el lector previamente familiarizado con el Quijote se desfamiliariza al principio, dado que su conocimiento previo de la personalidad de Sancho es diferente en El viaje infinito de Sancho Panza. Pero poco a poco, el lector encuentra ejes que unen a los Sanchos de Cervantes y de Sastre.

13 La cognición es la adquisición, organización y el uso de los conocimientos. Ulric Neisser, Cognition and Reality: Principles and Implications of Cognitive Psychology (San Franciasco: W. H. Freeman, 1976) 1. 
nuevo tipo de comportamiento con don Quijote. Quizá lo más difícil que Sancho tiene que aprender durante su servicio como escudero es cómo entender a dos tipos de personas que él no puede ver: los encantadores y Dulcinea ${ }^{14}$. Al percatarse de esto, pasa por un proceso de quijotización ${ }^{15}$. Durante ese lento y largo proceso, Sancho adopta características de su amo y muchas veces actúa como él ${ }^{16}$. Esta transformación le permite a Sancho obtener una profunda comprensión de la teoría de la mente y llega a ser capaz de leer la mente de su amo. Leer la mente es la habilidad de explicar el comportamiento de otras personas en cuanto a sus pensamientos, sentimientos, creencias y deseos ${ }^{17}$. Sancho es capaz de cambiar su personalidad para ajustarse al comportamiento de don Quijote. Como plantea O'Connell, somos lo que somos gracias a otra gente; es decir, uno se forma como un individuo por influencia de otros ${ }^{18}$. Nuestras relaciones también son producto de la información de la mente, por lo que pensamos lo que otros piensan ${ }^{19}$. Sancho es quien es gracias a su amo, y el contexto en que viven él y su amo. Sancho, entonces, conforme a Harris, es un agente racional:

For a planful, rational agent, it is important to be able to (1) identify the status quo (2) hold possible situations in mind (3) adopt pro or con attitudes toward those situations (4) select between actions in terms of whether they increase the likelihood of situations for which the agent has a pro attitude and/or reduce the likelihood of situations for which the agent has a con attitude. Thus, the execution of

14 Mancing (2011), 126.

15 Salvador de Madariaga, Guía del lector del «Quijote»: Ensayo psicológico sobre el "Quijote» (Madrid: Ríos Rosas; Barcelona: Cortes, 1926) 139-51.

16 Hipólito R. Romero Flores, Biografia de Sancho Panza: filósofo de la sensatez (Barcelona: Aedos, 1969) 193-214.

17 Lisa Zunshine, Why We Read Fiction: Theory of Mind and the Novel (Columbus: Ohio State University Press, 2006) 6.

18 Sanjida O'Connell, Mindreading: An Investigation into How We Learn to Love and Lie (Nueva York: Doubleday, 1998) 1.

19 O'Connell, 3. 
deliberate, planful action presumes an agent with some awareness of his or her pro or con attitudes towards possible situations ${ }^{20}$.

Sancho, como el agente en el Quijote, tiene que estar en condiciones de predecir todas las posibles respuestas de su amo. Asimismo, puede cambiar diferentes situaciones presentadas en la novela a favor de su pretensión. En el capítulo xx de la primera parte, Sancho ata las patas de Rocinante para que don Qujote no pueda avanzar en la oscuridad, porque él (Sancho) teme y ve que su amo está muy entusiasmado por la posible aventura. Como el escudero no quiere que su amo se marche para encontrar una aventura y lo deje solo, empieza a rogarle y a darle razones de por qué él (don Quijote) no no debe marcharse.

Señor, yo no sé por qué quiere vuestra merced acometer esta tan temerosa aventura; ahora es de noche, aquí no nos ve nadie; bien podemos torcer el camino y desviarnos del peligro, aunque no bebamos en tres días; y pues no hay quien nos vea, menos habrá quien nos note de cobardes; . . . que quien busca el peligro parece en él. . . Por un solo Dios, señor mío, que no se me faga tal desaguisado; ... . dilátelo, a lo menos hasta mañana; que, . . . , no debe de haber desde aquí al alba tres horas, porque la boca de la bocina está encima de la cabeza, y hace la media noche en la línea del brazo izquierdo ${ }^{21}$.

Sancho trata de aducir razones que influyan en que su amo cambie de decisión. Pero don Quijote está tan convencido de que va a emprender una nueva aventura que no le hace caso a su escudero. Viendo que es incapaz de convencer a don Quijote, decide «aprovecharse de su industria», y como es labrador, le sale bien el truco: «Cuando apretaba las chinchas al caballo, bonitamente y sin ser sentido, ató con el cabestro de su asno ambos pies a Rocinante, de manera que cuando don Quijote se quiso partir, no pudo, porque el caballo no se

20 Paul Harris, «Desires, Beliefs, and Language», Theories of Theories of Mind (Nueva York: Cambridge University Press, 1996) 209.

21 Miguel de Cervantes (John J. Allen, ed.) El ingenioso hidalgo don Quijote de la Mancha (Madrid: Cátedra, 2008) 280. 
podía mover sino a saltos $\rangle^{22}$. Este instante recuerda que cuando se tiene un deseo quiere que el mundo cambie para cumplir su deseo ${ }^{23}$. Sancho desea que su amo permanezca en el lugar, y sabiendo que cree en los encantamientos y en el destino, le inventa una historia ficticia para impedir la impetuosa aventura de su amo: «Ea, señor, que por el cielo, conmovido de mis lágrimas y plegarias, ha ordenado que no se pueda mover Rocinante; y si vos queréis porfiar, y espolear, y dalle, será enojar a la Fortuna y dar coces, como dicen, contra el aguijón» ${ }^{24}$. Obviamente, don Quijote cree en los encantadores tanto como otros caballeros andantes, por lo que no le queda otra opción más que esperar hasta que amanezca.

Otra prueba de la capacidad cognitiva del Sancho cervantino es que penetra en los pensamientos y futuras acciones formadas en la mente de su amo. Exhibe esa habilidad en el capítulo x de la segunda parte cuando el amo y el escudero están cerca del Toboso, el pueblo donde vive Dulcinea, y don Quijote le pide que le envíe a Dulcinea un recado. El escudero debe ir al Toboso y hablar con Dulcinea, luego venir a ver a su amo y contarle todo lo que ha sucedido. Como Sancho está consciente de que Dulcinea es una creación imaginaria de su amo y que no existe ninguna mujer en el Toboso con ese nombre (y que también sabe que don Quijote está bien convencido que su princesa Dulcinea vive en el Toboso), tiene que inventar una historia para engañar a su amo. De camino piensa en mil opciones, junto con las cuales reflexiona sobre las locuras de su amo. Como Sancho sabe que su amo está convirtiendo la verdad en una fantasía, tiene que engañarlo de forma que encaje y represente el mundo caballeresco en el que vive su amo. Por tanto, es consciente de que él es quien ve la realidad y su amo quien la convierte en imaginación. Don Quijote carece de una percepción del mundo real. Sus ilusiones se convierten

22 Cervantes (2008), 281.

23 O'Connell, 79.

24 Cervantes (2008), 281. 
a una «percepción falsa» ${ }^{25}$, por eso Sancho crea una réplica falsa o irreal, para manipular la percepción del Quijote, ser capaz de engañarlo $\mathrm{y}$ hacer la transformación de lo real a lo imaginario ${ }^{26}$.

Siendo, pues, loco, como lo es, y de locura que las más veces toma unas cosas por otras, y juzga lo blanco por negro y lo negro por blanco, como se pareció cuando dijo que los molinos de viento eran gigantes, y las mulas de los religiosos dromedarios, y las manadas de carneros ejércitos de enemigos, y otras muchas cosas a este tono, no será muy difícil hacerle creer que una labradora, la primera que me topare por aquí, es la señora Dulcinea; y cuando él no lo crea, juraré yo; y si él jurare, tornaré yo a jurar; y si porfiare, porfiaré yo más, y de manera que tengo de tener la mía siempre sobre el hito, venga lo que viniera ${ }^{27}$.

Para su suerte, vienen tres mujeres labradoras, y Sancho ve la posibilidad de engañar a don Quijote. Le desinforma que una de las mujeres es Dulcinea, y como no lo puede convencer, le dice que su Dulcinea está encantada, una mentira obvia, en la que tiene que creer su amo. Sancho conoce bien a su amo, incluso sus deseos y sus pensamientos, algo que le facilita leer su mente. Y como la conciencia de Sancho Panza no puede solo aproximarse a sí mismo, porque está en intensa relación con la de don Quijote, manipula la situación, desde el razonamiento de don Quijote, interpretada de su manera ${ }^{28}$. Según el planteamiento de Mancing:

Sancho knows [1] that Don Quixote believes [2] that evil enchanters want [3] to foil his desire [4] to gain fame as a knight errant;

25 Neisser, 130-31.

26 Mancing (2011), 125.

27 Miguel de Cervantes, ed. John J. Allen, Segunda parte del Ingenioso Caballero Don Quijote de la Mancha (Madrid: Cátedra, 2009) 106.

28 Alan Palmer, Fictional Minds (Lincoln: University of Nebraska Press, 2004) 143. Palmer también plantea que los humanos, como los personajes literarios pueden predecir y explicar las acciones de otros usando los recursos de sus propias mentes. Para adivinar el siguiente paso de la gente, los humanos y los personajes pueden manipular la situación cambiando sus propias acciones según el gusto del otro agente (143). 
therefore, he (Sancho) is sure [5] that he can make Don Quixote believe [6] that a peasant woman is Dulcinea ${ }^{29}$.

Comprender lo que está en la mente de otra persona implica dos habilidades cognitivas: una comprensión de cómo está vinculada la atención a las metas y entender las emociones ${ }^{30}$. Sancho está consciente de las emociones y el entendimiento de su amo, como se puede notar en los ejemplos anteriores. Estos episodios que revelan la mente de Sancho en acción u otros son claras pruebas de la teoría de la mente del personaje cervantino ${ }^{31}$ y su profunda cognición se verá en la obra de Sastre también.

\section{La teoría de la mente de Sancho reacentuado}

El Sancho que nos presenta Sastre ejerce más autoridad al principio de la obra. El momento de la obra cuando Sancho se retira un poco como personaje y el don Quijote se revela más como personaje principal ocurre después del episodio de los leones. En el Quijote, después del episodio de los leones (capítulo XvI de la segunda parte) en que el don Quijote original «vence» al león y regresa a casa, su escudero es quien muchas veces anima a su amo y tiene un papel significativo en la persuasión de salir otra vez, y un papel prominente en la segunda parte de la novela de Cervantes. En El viaje infinito de Sancho Panza el desarrollo de ambos personajes es inverso.

En su obra Sastre reconcibe el personaje de Sancho cervantino y lo presenta en un nuevo contexto. Es decir, se reacentúa la imagen de Sancho Panza. Como este dramaturgo es un «infatigable explorador de fondos teatrales $\rangle^{32}$, reacentúa, recrea y reintroduce el personaje de Sancho en un nuevo género y en un contexto histórico, político y

29 Mancing (2011), 126; destacado en original.

30 O'Connell, 63.

31 Mancing (2011), 126.

32 Anita Johnson, «Alfonso Sastre: Evolución y síntesis en el teatro español contemporáneo», Anales de la literatura española contemporánea, 17, 1/3 (1992): 206. 
sociológico. El nuevo Sancho, aunque no ha adquirido nuevos aspec$\operatorname{tos}^{33}$, se ha convertido en un personaje único. La figura de Sancho se adecua a los gustos y a la lógica de la época en la que escribe Sastre. Como plantea Lisa Zunshine, las circunstancias cambian, las mentes cambian y los lectores cambian también ${ }^{34}$. Así, Sastre opta por ajustar al personaje Sancho del Quijote a los límites y expectativas socioliterarias de sus tiempos. Cambia ciertos aspectos del escudero cervantino con el fin de hacerle más disponible y aprovechable para los lectores de su época, y carga su obra de significados sociales y políticos contemporáneos ${ }^{35}$. No obstante, un aspecto que el Sancho de Sastre como personaje reacentuado no ha cambiado es su forma de pensar.

La percepción sobre el personaje de Sancho para Sastre como lector no es muy diferente de la de otros lectores generales. Aunque la percepción general de Sancho, la istina ${ }^{36}$ sobre Sancho, no es tan diferente para Cervantes o para Sastre, la forma de representación al principio del Quijote y el Viaje infinito de Sancho Panza es un cambio de perspectiva para los lectores. Al principio de su novela, Cervantes nos presenta a un Sancho débil, con poca voluntad, que se convierte poco a poco en un hombre más inteligente. Sin embargo, me inclino a creer que varios lectores del Quijote perciben la imagen de Sancho como un hombre muy listo y previsor. Además, hay una verdad sobre la personalidad de Sancho, la istina de Sancho, que se percibe de don Quijote, que no se puede cambiar: Sancho es el escudero de don Quijote; Sancho es el gracioso quien le hace reír a su amo; Sancho es inocente, pero listo; Sancho crece, mejora y desarrolla su

33 El nombre Sancho no ha cambiado, el personaje reclama ser el escudero de don Quijote, conoce su oficio y a su amo muy bien.

34 Zunshine, 76.

35 Javier Huerta Calvo, «Don Quijote en la escena contemporánea», Don Quijote desde el siglo XXI (Madrid: Centro de Estudios Cervantinos, 2005) 93.

36 Bakhtin plantea dos definiciones de la verdad: pravda es la verdad subjetiva; istina es la verdad objetiva y universal. La istina es constante y no cambia, mientras pravda es la verdad subjetiva. Así, se percibe una istina de Sancho cervantino con la cual muchos lectores pueden estar de acuerdo. Y ese es el oficio de Sancho, su trabajo como escudero del Quijote, su proceso de quijotización entre otros aspectos característicos. Mikhail M. Bakhtin. Towards a Philosophy of the Act, Michael Holquist and Vadim Liapunov, eds. (Austin: University of Texas Press, 1993) 37, 41, 88. 
personalidad por el proceso de quijotización. Así, en El viaje infinito de Sancho Panza, conserva esas características, pero se presenta de modo desfamiliarizado, porque el Sancho sastreano no desarrolla su personalidad por un proceso de quijotización, sino que aparece ya formado como personaje completo, ya quijotizado. Sabe muy bien que es un personaje de la novela de Cervantes, y puede discutir los acontecimientos de la novela, aun cambiar algunos aspectos ajustándolos a sus propios intereses.

Doctor: Así, pues. Valdepeñas es el nombre de aquel lugar de la Mancha de cuyo nombre no quería acordarse el escritor..., ¿cómo se llama el escritor? (Consulta unas notas) Murió en 1616... Miguel de Cerpontes.

SANCHO: Cervantes.

Doctor: Aquí dice Cerpontes. (Las monjas miran amenazadoramente a Sancho)

SANChO: (Asustado) Será Cerpontes ${ }^{37}$.

La introducción de Sancho deja la impresión de que el personaje es diferente del que está en el Quijote. Sin embargo, el Sancho sastreano presenta numerosos aspectos de personalidad que comparte con su precedente cervantino. En El viaje infinito, «Sastre lleva a cabo una inversión del mito literario» y de esa manera introduce «otro don Quijote» y «otro Sancho Panza y esta ambigüedad se constituye en valor fundamental del experimento dramático en el que el espectador ha de sentirse a un tiempo en un mundo familiar y extraño» ${ }^{38}$. Esta obra representa un proyecto ambicioso para el propio Sastre, porque él tenía que presentar de manera propia a los legendarios protagonistas de Cervantes ${ }^{39}$. Desde el principio del Viaje infinito de Sancho

37 Alfonso Sastre, El viaje infinito de Sancho Panza (Madrid: Sociedad general de autores, 1984) 16.

38 Mariano de Paco, «El teatro de Alfonso Sastre», Teatro español contemporáneo: autores y tendencias (Kassel: Reichenberger, 1995) 147; destacado en original.

39 Alfonso Sastre, «Notas para una sonata en mi (menor)», Alfonso Sastre (Murcia: Secretariado de Publicaciones, Universidad de Murcia, 1993) 38. 
Panza, Sancho comienza su discurso en un tono afirmativo ${ }^{40}$ e invoca su opinión sobre el Quijote:

En cuanto a este libro, mucho es lo que habría que discutir, y no porque yo no guarde un gran respeto, que todos merece, a su difunto autor don Miguel de Cervantes - o Cerpontes, o como quiera usted que se llame este gran maestro de las letras-, sino porque el manuscrito de que él se sirvió, debido a la pluma arábiga de Cide Hamete Benengeli, contiene algunas graves inexactitudes, y un servidor puede decirlo pues es parte muy interesada en este asunto ${ }^{41}$.

El personaje trae a la superficie su perspectivismo, y le echa la culpa a Cide Hamete, pues sabe que el doctor conoce la obra de Cervantes, donde la intención del narrador era hacerle al lector pensar que Cide Hamete Benengeli miente: «No. No podría decirse eso. ¡Todo eso es mentira! Esta historia hay que contarla de nuevo o nadie sabrá nunca nada de lo que pasó en realidad ${ }^{42}$.

Para Emilio de Miguel Martínez, en El viaje infinito de Sancho Panza Sastre nos ofrece «los perfiles de un Sancho no menos luminosamente loco que el caballero ${ }^{43}$. Pero al mirar el fondo del texto, se puede percibir que Sancho trata de fingir estar loco por una razón: para convencer a don Quijote que él es el Quijote primeramente visto en la obra de Cervantes. Todo lo que hace Sancho desde el principio de la obra de Sastre hasta el final tiene un propósito cuidadosamente planeado que le sirve para recrear la completa imagen de don Quijote de la Mancha en el personaje de Alonso Quijano.

Sancho da su interpretación del inicio de las aventuras del hidalgo cervantino, y cuando el doctor le pregunta si don Quijote tiene un pasado, contesta: «Así era sólo que sus anteriores aventuras son

40 Aunque se nota que él todavía suele rendirse cuando se trata de conocimientos, como lo hacía varias veces en la obra de Cervantes.

41 Sastre (1984), 17.

42 Sastre (1984), 17.

43 Emilio de Miguel Martínez, Teatro español: 1980-2000. Catálogo visitado (Salamanca: Universidad de Salamanca, 2002) 150. 
desconocidas, por haber caído sobre ellas las brumas de la leyenda y el olvido de la historia, no sé si me explico» ${ }^{44}$. Prosigue contando una historia sobre cómo Alonso Quijano se convirtió en don Quijote: todo esto era a causa del sueño de Sancho donde él ve cómo Quijano lucha contra los gigantes y gana, y al día siguiente va a la casa de Alonso Quijano para revelarle su verdadera persona. Sancho rechaza el comienzo de la novela de Cervantes y reclama que todo es mentira; una mentira en la que el héroe cervantino salió sólo de la casa la primera vez en búsqueda de aventuras. Sancho está tan entusiasmado con su nueva historia que se apropia de las características de otros personajes de la novela. Él es quien pasa días de claro en claro leyendo los mejores libros del mundo, y quien presenta a Dulcinea como la princesa amada por don Quijote; también hace el papel de Sansón Carrasco, quien en la segunda parte del Quijote insiste en la salida del amo y escudero cervantino, convencido de que va a salir una segunda parte del libro sobre ellos. El Sancho de Sastre reclama que su sueño es tan real que no cabe duda deque Alonso Quijano es don Quijote. Con esta convicción le cuenta su sueño a Alonso, con el fin de convencerle salir en busca de aventuras. Después de muchos esfuerzos, el protagonista de Sastre logra convencer a Quijano de que el último es el caballero andante don Quijote, y en el cuadro IV finalmente don Quijote y Sancho salen para buscar aventuras. El Quijote sastreano admite que aunque no sabe por qué han salido, es mejor escapar de su casa. Las únicas personas que le hacían compañía eran su ama de casa, su sobrina, el cura y el barbero. Lo cuenta a Sancho en la siguiente forma:

D. Quijote. (De lo más maltrecho y dolorido, tanto que no se puede levantar de los suelos) Ya parece que me voy recordando, maestro Sancho, de muy olvidadas lecciones de la vida: así se disimula, por lo que más quieras, mi fallo de esta tarde y vayamos adelantando en lo posible, porque eso que dices de volver a casa, de eso nada, ahora

44 Sastre (1984), 19. 
que hemos empezado esta cosa que no sé lo que es, pero que siempre será mejor que lo que me estaba pasando en Valdepeñas, que eso sí es horrible, por maltrecho que ahora me vea, que no me puedo ni mover, pero menos me podía mover allá en mi cama, muerto de no sé cuántas tristezas que allí me atenazaban y no me permitían ni moverme: así que no me vengas con eso de volver a aquella miseria, sino que sigamos por esos campos a ver qué pasa, y a ver si me acomodo un poco a esto que no sé si es absurdo, pero que por lo menos no es horrible como aquella vida cotidiana como ama y con sobrina y con un cura y con un barbero y con un bachiller y otras terribles especies de la humanidad ${ }^{45}$.

Don Quijote le admite a Sancho que ahora está listo para salir a nuevas aventuras, aunque le parezca absurdo su comportamiento. La razón de don Quijote para salir es su vida aburrida en Valdepeñas y la casa, que le parece a su tumba. Don Quijote empieza a creerle y a depender de Sancho. Como este nota la dependencia de Quijote, lo empieza a manipular y a tratar de convertirlo al personaje principal conocido del Quijote. Ahora es Sancho quien ve gigantes y no molinos de viento, castillos y no ventas. En el fondo todas estas imaginaciones son invenciones de Sancho, quien manipula a su amo para que vuelva a ser el mismo don Quijote de la obra de Cervantes. Por el conocimiento y la habilidad de manipular a su amo, Sancho reacentuado, como su homólogo, logra un final de los acontecimientos y las aventuras deseables. Sancho es quien dirige a don quijote, porque él no recuerda nada ni sabe quién es, pero poco a poco se sanchifica en esta obra de teatro; después del episodio donde Sancho y Quijote se encuentran con los leones, él (Alonso Quijano de Sastre) empieza a actuar como el Quijote de la novela de Cervantes. Desde ese punto, el Quijote de Sastre comienza a comportarse como un caballero valiente, adelantándose para encontrar una aventura sin el consejo o las instrucciones de su ayudante Sancho. Lo que invoca antes de la aventura lo hace

45 Sastre (1984), 38-39. 
asemejarse bastante al personaje principal de la novela de Cervantes. Dice el personaje sastreano: «-Sí que has dicho: “leones”. ¿Y qué? ¿Leoncitos a mí? ¿A mí leoncitos y a tales horas? Abre la puerta a esas fierecillas y verán lo que les sucede: pues no faltaría más ${ }^{46}$. Esta parte es el punto culminante de las obras discutidas de Sastre y Cervantes, porque en adelante se ve un cambio drástico en la personalidad de los protagonistas de las dos obras. En el Quijote el caballero andante se retira un poco y su escudero deja ver su personalidad y sus habilidades directivas. Al contrario, en El viaje infinito de Sancho Panza es Sancho quien se retira después del episodio, porque su amo ahora sabe quién es de verdad y empieza a actuar de distinta manera, relevando más semejanzas con el personaje de Cervantes.

\section{Conclusiones}

Al principio del Viaje infinito de Sancho Panza se piensa que Sancho es otro personaje, quien después de leer la obra de Cervantes quiere identificarse con el personaje del escudero de don Quijote. Sin embargo, en la obra de Sastre puede entenderse sin conocimiento previo del Quijote. Sancho también puede percibirse como un personaje único e individual. Si un lector está familiarizado con el personaje de la obra de Cervantes, es probable que identifique al Sancho de Sastre como al mismo del Quijote ${ }^{47}$. Aunque Sancho está reacentuado en El viaje, no vuelve a ser un personaje totalmente nuevo, porque su mentalidad no cambia. Las diferencias entre ambos son muy sutiles, se revelan en la forma de hablar de ambos, o de cómo domina cada personaje en su respectiva versión. La caracterización de Sancho de ser de «poca sal en la mollera» es errónea, especialmente en El viaje infinito de Sancho Panza, porque parece simple, pero revela una compleja mentalidad a lo largo de la obra. Se lee la obra de Sastre acordándose de

46 Sastre (1984), 74.

47 Dicho esto, el lector implícito, aun sin poseer conocimiento previo del Quijote, va a sentir la recepción de ese Quijote al revés que presenta El viaje infinito de Sancho Panza. 
la imagen de Sancho y su ser quijotesco, su inocencia e inteligencia presentada en el Quijote. Su capacidad de leer los pensamientos de su amo y actuar conforme a la situación le innova como un personaje libre y lleno de cognición. También en El viaje infinito de Sancho Panza, este personaje desempeña un papel importante en el desarrollo del personaje de Alonso Quijano, de lo que el Sancho sastreano es muy consciente. Sin los pensamientos, intenciones y persuasiones de Sancho, Alonso Quijano nunca sabría que él es el caballero andante llamado don Quijote. 
